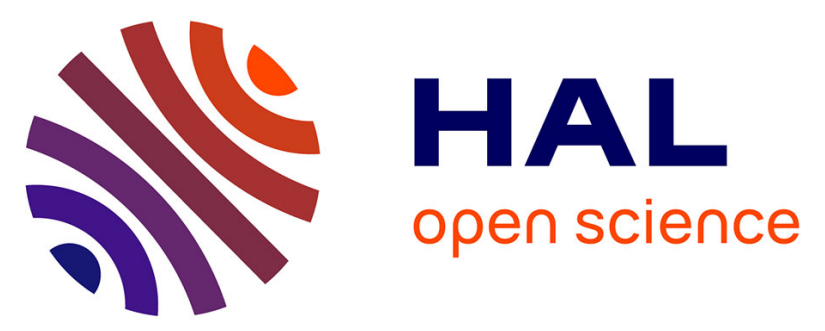

\title{
Incidence, predictors and clinical impact of electrical storm in patients with left ventricular assist devices: new insights from the ASSIST-ICD study
}

R.P. Martins, Christophe Leclercq, Hamed Bourenane, Vincent Auffret, S. Boulé, V. Loobuyck, Camille Dambrin, P. Mondoly, F. Sacher, P. Bordachar, et al.

\section{To cite this version:}

R.P. Martins, Christophe Leclercq, Hamed Bourenane, Vincent Auffret, S. Boulé, et al.. Incidence, predictors and clinical impact of electrical storm in patients with left ventricular assist devices: new insights from the ASSIST-ICD study. Heart Rhythm, 2019, 16 (10), pp.1506-1512. 10.1016/j.hrthm.2019.06.021 . hal-02169759

\section{HAL Id: hal-02169759 \\ https://hal.science/hal-02169759}

Submitted on 12 Jun 2020

HAL is a multi-disciplinary open access archive for the deposit and dissemination of scientific research documents, whether they are published or not. The documents may come from teaching and research institutions in France or abroad, or from public or private research centers.
L'archive ouverte pluridisciplinaire HAL, est destinée au dépôt et à la diffusion de documents scientifiques de niveau recherche, publiés ou non, émanant des établissements d'enseignement et de recherche français ou étrangers, des laboratoires publics ou privés. 


\section{Incidence, predictors, and clinical impact of electrical storm in patients with left ventricular assist devices: New insights from the ASSIST-ICD study}

Raphaël P. Martins, MD, PhD, ${ }^{*}$ Christophe Leclercq, MD, PhD, * Hamed Bourenane, MD, * Vincent Auffret, MD, PhD, ${ }^{*}$ Stéphane Boulé, MD, ${ }^{\dagger}$ Valentin Loobuyck, MD, ${ }^{\dagger}$ Camille Dambrin, MD, PhD, ${ }^{\ddagger}$ Pierre Mondoly, MD, ${ }^{\ddagger}$ Frédéric Sacher, MD, PhD, $\$$ Pierre Bordachar, MD, ${ }^{\S}$ Michel Kindo, MD, PhD, "Thomas Cardi, MD, Philippe Gaudard, MD, "Philippe Rouvière, MD, "Magali Michel, MD, " Jean-Baptiste Gourraud, MD, ${ }^{\#}$ Pascal Defaye, MD, ${ }^{* *}$ Olivier Chavanon, MD, PhD, ** Caroline Kerneis, MD, ${ }^{\dagger \dagger}$ Walid Ghodhbane, MD, ${ }^{\dagger \dagger}$ Edeline Pelcé, MD, ${ }^{\neq \ddagger}$ Vlad Gariboldi, MD, PhD, ${ }^{\ddagger}$ Matteo Pozzi, MD, Daniel Grinberg, MD, Pierre-Yves Litzler, MD, PhD, ${ }^{\|\|}$Frédéric Anselme, MD, ${ }^{\|\|}$Gerard Babatasi, MD, PhD, Annette Belin, MD, ${ }^{\top \Phi}$ Fabien Garnier, MD, ${ }^{\# \#}$ Marie Bielefeld, MD, ${ }^{\# \#}$ David Hamon, MD, ${ }^{* * *}$ Nicolas Lellouche, MD, PhD, ${ }^{* * *}$ Bertrand Pierre, MD, ${ }^{\dagger \dagger \dagger}$ Thierry Bourguignon, MD, ${ }^{\dagger \dagger}$ Romain Eschallier, MD, PhD, ${ }^{\ddagger \neq \ddagger}$ Nicolas D'0strevy, MD, ${ }^{\ddagger \neq \ddagger}$

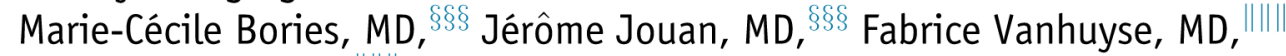
Nicolas Sadoul, MD, ${ }^{\|\| \|}$Erwan Flécher, MD, PhD, ${ }^{*}$ Vincent Galand, MD*

From the *Univ Rennes, CHU Rennes, INSERM, LTSI - UMR 1099, Rennes, France, 'Department of Cardiology, CHU Lille, Institut Coeur-Poumons, Lille, France, ${ }^{\star}$ Department of Cardiology, CHU de Toulouse, Toulouse, France, ${ }^{\S}$ Hôpital Cardiologique du Haut-Lévêque, Université Bordeaux, Bordeaux, France, "Département de chirurgie cardiovasculaire, Hôpitaux Universitaires de Strasbourg, Strasbourg, France, "Department of Cardiac Surgery, Anesthesiology and Critical Care Medicine, Arnaud de Villeneuve Hospital, CHRU Montpellier, Montpellier, France, ${ }^{*}$ Department of Cardiology and Heart Transplantation Unit, CHU Nantes, Nantes, France, **Department of Cardiology and Cardiovascular Surgery, CHU Michallon, Grenoble, France, ${ }^{\dagger}$ Department of Cardiology and Cardiac Surgery, Bichat-Hospital, Paris, France, ${ }^{\dagger}$ Department of Cardiac Surgery, La Timone Hospital, Marseille, France, ${ }^{\S \S}$ Department of Cardiac Surgery, "Louis Pradel" Cardiologic Hospital, Lyon, France, "II Department of Cardiology and Cardiovascular Surgery, Hospital Charles Nicolle, Rouen, France, ${ }^{\boldsymbol{\top}}$ Department of Cardiology, University of Caen and University Hospital of Caen, Caen, France, ${ }^{\# \#}$ Department of Cardiology and Cardiac Surgery, University Hospital, Dijon, France, ***Department of Cardiology and Cardiac Surgery, AP-HP CHU Henri Mondor, Créteil, France, ${ }^{\dagger}$ Department of Cardiology and Cardiac Surgery, Tours University Hospital, Tours, France, ${ }^{+}$Department of Cardiology, CHU Clermont-Ferrand, Clermont-Ferrand, France, ${ }^{\S \S \S}$ Department of Cardiology, European Georges Pompidou Hospital, Paris, France, and \|\|$\|$ Department of Cardiology and Cardiac Surgery, CHU de Nancy, Hopital de Brabois, Nancy, France.

This research was supported in part by the French Federation of Cardiology. Dr Leclercq and Dr Mondoly have received honoraria from Biotronik, Boston Scientific, Medtronic, Abbott, and LivaNova. Dr Kindo has received honorarium from HeartWare. Dr Defaye has received honoraria from Boston Scientific, Medtronic, Abbott, and LivaNova. Dr Chavanon has received honorarium from Thoratec. Dr Anselme has received honoraria from Medtronic, LivaNova, Boston Scientific, and Abbott. Dr Garnier has received honoraria from Boston Scientific and Medtronic. Dr Martins has received honoraria from Medtronic. Abbott. and LivaNova. The rest of the authors report no conflicts of interest. ClinicalTrials.gov identifier: NCT02873169.

Raphaël P. Martins, Service de Cardiologie et Maladies Vasculaires, CHU de Rennes, 2 rue Henri Le Guilloux, 35000 Rennes, France. E-mail address: raphael. martins@chu-rennes.fr. 
BACKGROUND Ventricular arrhythmias (VAs) can occur after continuous flow left ventricular assist device (LVAD) implantation as a single arrhythmic event or as electrical storm (ES) with multiple repetitive VA episodes.

OBJECTIVE We aimed at analyzing the incidence, predictors, and clinical impact of ES in LVAD recipients.

METHODS Patients analyzed were those included in the multicenter ASSIST-ICD observational study. ES was consensually defined as occurrence of $\geq 3$ separate episodes of sustained VAs within a 24hour interval.

RESULTS Of 652 patients with an LVAD, $61(9 \%)$ presented ES during a median follow-up period of 9.1 (interquartile range [IQR] 2.522.1) months. The first ES occurred after 17 (IQR 4.0-56.2) days post LVAD implantation, most of them during the first month after the device implantation (63\%). The incidence then tended to decrease during the initial years of follow-up and increased again after the third year post LVAD implantation. History of VAs before
LVAD implantation and heart failure duration $>84$ months were independent predictors of ES. The occurrence of ES was associated with an increased early mortality since 20 patients $(33 \%)$ died within the first 2 weeks of ES. Twenty-two patients (36.1\%) presented at least 1 recurrence of ES, occurring 43.0 (IQR 8.0-69.0) days after the initial ES. Patients experiencing ES had a significantly lower 1-year survival rate than did those free from ES (log-rank, $P=.039)$.

CONCLUSION There is a significant incidence of ES in patients with an LVAD. The short-term mortality after ES is high, and one-third of patients will die within 15 days. Whether radiofrequency ablation of arrhythmias improves outcomes would require further studies.

KEYWORDS Electrical storm; Mortality; Left ventricular assist device; Ventricular arrhythmia; Ventricular fibrillation; Ventricular tachycardia

\section{Introduction}

Continuous flow left ventricular assist devices (LVADs) have emerged as an alternative therapy for patients with end-stage heart failure, and implantation rates are constantly increasing. ${ }^{1}$ The long-term unloading of the left ventricle mediated by the LVAD decreases heart failure symptoms and improves quality of life.

However, many complications can occur during followup, such as stroke, bleeding, infections, or ventricular arrhythmias (VAs). Indeed, the rates of VAs occurring in the early postoperative period or during follow-up have been described to range between $22 \%$ and $24.8 \%{ }^{2,3}$ and between $11.6 \%$ and $39.0 \%,{ }^{3-9}$ respectively, after $8-15$ months of follow-up. Antiarrhythmic drugs and/or ablation of the ventricular substrate could help to avoid recurrences and improve outcomes.

The presentation of VAs is highly variable and can occur as a single ventricular tachycardia (VT) or fibrillation (VF) event or as electrical storm (ES) with multiple repetitive VT/VF episodes. ES is a life-threatening event in patients without an LVAD, increasing mortality, and hospitalization rates, both in the acute phase and during long-term followup, ${ }^{10}$ but its impact in patients with an LVAD has been evaluated only in a small series of patients. ${ }^{11}$ Thus, we aimed at analyzing the incidence, predictors, and clinical impact of ES in the large cohort of patients included in the ASSIST-ICD study.

\section{Methods}

\section{Study design}

ASSIST-ICD is a retrospective multicenter observational study (ClinicalTrials.gov identifier NCT02873169) of durable mechanical circulatory support devices implanted at 19 tertiary French centers. The methods of this study have been previously published. ${ }^{6}$

Briefly, patients 18 years and older implanted with axial HeartMate II (Abbott, Chicago, IL), Jarvik2000 (Jarvik
Heart, Inc., New York, NY), or centrifugal HeartWare pumps (Medtronic, Columbia Heights, MN) between February 2006 and December 2016 were included in the final analysis. The type of pump implanted depended on the local heart team's decision in each center. Exclusion criteria were as follows: patients who underwent total artificial heart placement or pulsatile flow LVAD implantation, those with a history of heart transplantation, and VentrAssist (Ventracor, Chatswood, New South Wales, Australia) recipients. Patients lost to follow-up or LVAD recipients with lacking data were excluded from the final analysis.

This study was approved by the regional ethics committees, the French Advisory Committee on the Treatment of Research Information in the Field of Health (CCTIRS), and the French National Commission of Informatics and Civil Liberties (CNIL). A nonopposition letter was sent to patients as requested by French authorities for retrospective studies.

\section{Baseline assessment and follow-up}

Baseline data, including demographic characteristics, cardiac disease and heart failure, history of VAs and supraventricular tachycardia before or after LVAD implantation, echocardiographic data, and blood chemistry values, were collected from hospital files for all enrolled patients. Regarding perioperative data, data on combined surgery with LVAD implantation and need of right extracorporeal life support were collected. Follow-up was performed according to each institution's protocols. The last day of follow-up was December 31, 2016, the date of heart transplantation, or death, whichever occurred first.

\section{VAs}

As previously described, ${ }^{6}$ VAs were defined as sustained ( $>30$ seconds) VT or VF without an acute reversible cause and treated medically, by external electrical shock, or by appropriate therapy from an implantable cardioverterdefibrillator (ICD; antitachycardia pacing or shock). The 
type of arrhythmias was collected. ES was consensually defined as the occurrence of $\geq 3$ separate episodes of sustained VAs within a 24-hour interval.

In the article, ${ }^{6}$ we included a subset of the entire ASSISTICD cohort and consequently, the number of LVAD recipients with ES is different compared to the number of patients with ES in the current paper. Indeed, in this work, we included the overall ASSIST-ICD population.

\section{Study end points}

The primary end points of the study were the rates of ES. Secondary end points included all-cause mortality during followup, depending on the occurrence of ES or not. Deaths were classified as cardiovascular death (cardiac or vascular cause) or noncardiac death.

\section{Statistical analysis}

Qualitative variables are expressed as number (percentage); continuous data as mean \pm SD or median (interquartile range [IQR]) depending on their distribution, which was assessed using the Kolmogorov-Smirnov test. Survival rates were summarized using Kaplan-Meier estimates, and log-rank tests were used to compare groups. Predictors of ES were analyzed using univariate and multivariate proportional hazards models (cumulative outcomes). The proportional hazards assumption was tested and verified for each covariate. All univariate analyses were performed on complete cases. For the purposes of multivariate analysis, assuming missing data were randomly missing, multiple imputation using Monte Carlo Markov chained equations was used to generate 10 data sets without missing values. Only 2 variables of interest had missing data: left ventricular end-diastolic diameter $(12.0 \%)$ and total bilirubin level $(13.7 \%)$. At this point, receiver operating characteristic curves were used on the original data to dichotomize continuous variables with a $P$ value of $<.1$ in univariate analysis using the Youden's index to choose the optimal cutoff. Variables with a $P$ value of $<.1$ in univariate analysis were included in the multivariate analysis to derive adjusted hazard ratios with their 95\% confidence intervals, which were then combined using Rubin's rule. Statistical analyses were performed using SPSS version 22 (IBM Corp., Armonk, NY).

\section{Results \\ Study population}

From 2006 to 2016, a total of 659 patients were implanted with a continuous flow LVAD and included in the study. Seven patients were excluded ( 3 patients received a VentrAssist device and 4 patients died during the LVAD surgery). Thus, a total of 652 patients were included in the final analysis. Of these patients, 61 (9\%) presented ES during a median period of 9.1 (IQR 2.5-22.1) months of follow-up. Patients' characteristics are described in Table 1. Briefly, patients presenting ES during follow-up had a significantly higher body mass index, a longer history of heart failure, and larger ventricles. A significantly higher proportion of patients with a history of VAs was observed in patients with ES (64.0\% vs $31.1 \% ; P<.001$ ), and consequently, these patients were more often implanted with an ICD. Of 39 patients having experienced VAs before LVAD implantation, 23 (59\%), 5 $(12.8 \%)$, and $11(28.2 \%)$ had VT, VF, or both VT/VF episodes, respectively. Interestingly, both groups had a similar proportion of the underlying heart disease and LVAD indication. Lastly, the type of LVAD implanted was similar between groups. Of note, patients with ES had a significantly higher VT-LVAD score than did those without ES (6.0 [4.75-8.0] vs 4.0 [2.0-6.0]; $P<.001$ ).

In multivariate analysis, history of VAs before LVAD implantation (hazard ratio $2.620 ; 95 \%$ confidence interval 1.484-4.627; $P=.001$ ) and heart failure duration $>84$ months (hazard ratio 1.966; 95\% confidence interval $1.074-3.597 ; P=.028)$ were independent predictors of the occurrence of ES (Table 2).

\section{Characteristics and temporal trend in ES occurrence after LVAD implantation}

Of 61 patients, 37 (61\%), 10 (16\%), and 14 (23.0\%) had VT, $\mathrm{VF}$, and both VT/VF episodes during the initial ES event, respectively. The relationship between the type of VAs before LVAD implantation and the type of VAs during ES in 39 patients with a history of arrhythmias is shown in Figure 1. As one can observe, patients having experienced VT episodes mainly had only VT recurrences during ES. Figure 1 also illustrates that 22 patients without VA (36.1\%) before LVAD implantation experienced at least 1 ES after LVAD implantation.

ES occurred after a median of 17 (IQR 4.0-56.2) days after LVAD implantation. As shown in Figure 2, the temporal trend in ES occurrence in LVAD recipients tended to follow a U-shaped curve. Indeed, most of the ES events occurred during the first month $(63 \%)$ after the implantation of the device. Twenty-two ES events occurred during the first week after LVAD implantation, including 6 within the first 24 hours of surgery. Thereafter, few ES events occurred during the first year after implantation and no event occurred during the following 2 years. After the third year, new ES episodes were observed (6 ES episodes in 89 patients alive after 1000 days of follow-up [7\%]). Three groups of patients experiencing ES were compared depending on the time of occurrence: early ES ( $<30$ days), late $\mathrm{ES}$ ( $>30$ days), and very late ES ( $>1000$ days). As shown in Supplemental Table 1, LVAD recipients who experienced very late ES had significantly more idiopathic cardiomyopathy, with a trend in longer heart failure duration and more history of supraventricular tachycardia.

In addition to the usual medical management with antiarrhythmic drugs and/or cardioversion/defibrillation shocks or antitachycardia pacing, 6 patients $(10 \%)$ had radiofrequency ablation of VAs. A total of 9 VTs were targeted: 1 was related to the LVAD cannula, 2 were bundle branch reentrant VTs, and the intrinsic myocardial scar was involved in 6 VTs (septal region $[\mathrm{n}=3]$, anterior region $[\mathrm{n}=2]$, and inferior 


\begin{tabular}{|c|c|c|c|}
\hline Variable & Patients with ES $(n=61)$ & Patients without ES $(n=591)$ & $P$ \\
\hline Age $(y)$ & $59.0(54.0-65.0)$ & $60.0(51.0-66.0)$ & .86 \\
\hline Men & $53(87)$ & $508(86.0)$ & .99 \\
\hline BMI $\left(\mathrm{kg} / \mathrm{m}^{2}\right)$ & $26.0(24.0-29.0)$ & $25.0(22.0-28.0)$ & .01 \\
\hline \multicolumn{4}{|l|}{ Heart failure etiology } \\
\hline Ischemic & $38(62.0)$ & $374(63.0)$ & \multirow{3}{*}{.61} \\
\hline Idiopathic & $19(31.0)$ & $159(27.0)$ & \\
\hline Other & $4(7.0)$ & $58(10.0)$ & \\
\hline Heart failure duration (mo) & $133.0(56.0-226.0)$ & $55.0(2.0-158.0)$ & $<.001$ \\
\hline \multicolumn{4}{|l|}{ Echocardiographic data } \\
\hline LVEDD before LVAD implantation (mm) & $73.0(66.0-76.0)$ & $69.0(63.0-75.0)$ & .008 \\
\hline LVEF before LVAD implantation (\%) & $20.0(15.0-23.0)$ & $20.0(15.0-25.0)$ & .176 \\
\hline \multicolumn{4}{|l|}{ History of arrhythmias } \\
\hline History of VAs & $39(64.0)$ & $184(31.0)$ & $<.001$ \\
\hline VT ablation before LVAD implantation & $4(7.0)$ & $32(5.0)$ & .938 \\
\hline History of supraventricular tachycardia & $36(59.0)$ & $266(45.0)$ & .051 \\
\hline \multicolumn{4}{|l|}{ Devices before LVAD implantation } \\
\hline ICD before LVAD implantation & $50(82.0)$ & $353(60.0)$ & .001 \\
\hline CRT before LVAD implantation & $23(38.0)$ & $175(30.0)$ & .245 \\
\hline \multicolumn{4}{|l|}{ Arrhythmic drugs before LVAD implantation } \\
\hline$\beta$-Blockers & $51(84)$ & $372(63.0)$ & .002 \\
\hline Amiodarone & $33(54.0)$ & $258(44.0)$ & .154 \\
\hline \multicolumn{4}{|l|}{ Laboratory values } \\
\hline Serum creatinine level $(\mu \mathrm{mol} / \mathrm{L})(n=598)$ & $123.0(98.0-154.0)$ & $113.0(86.0-147)$ & .135 \\
\hline Serum sodium level $(\mathrm{mmol} / \mathrm{L})(n=599)$ & $136.0(132.0-138.0)$ & $136.0(132.0-139.0)$ & .826 \\
\hline Total bilirubin level $(\mu \mathrm{mol} / \mathrm{L})(n=563)$ & $18.0(11.0-31.0)$ & $16.0(10.0-26.0)$ & .102 \\
\hline \multicolumn{4}{|l|}{ Type of LVAD } \\
\hline HeartMate II & $44(72.0)$ & $431(73.0)$ & \multirow{3}{*}{.273} \\
\hline HeartWare & $15(25.0)$ & $112(19.0)$ & \\
\hline Jarvik2000 & $2(3.0)$ & $48(8.0)$ & \\
\hline \multicolumn{4}{|l|}{ LVAD indication } \\
\hline Bridge to transplantation & $38(60.0)$ & $349(59.0)$ & \multirow{3}{*}{.829} \\
\hline Destination therapy & $21(34.0)$ & $226(38.0)$ & \\
\hline Bridge to decision/recovery & $2(3.0)$ & $16(3.0)$ & \\
\hline Combined surgery with LVAD & $9(15.0)$ & $86(15.0)$ & .882 \\
\hline Right ECLS during surgery & $7(11.0)$ & $74(12.0)$ & .975 \\
\hline VT-LVAD score & $6.0(5.0-8.0)$ & $4.0(2.0-6.0)$ & $<.001$ \\
\hline
\end{tabular}

Values are presented as median (interquartile range) or as $\mathrm{n}(\%)$.

$\mathrm{BMI}=$ body mass index; $\mathrm{CRT}=$ cardiac resynchronization therapy; ECLS = extracorporeal life support; $\mathrm{ES}=$ electrical storm; ICD = implantable cardioverterdefibrillator; LVAD = left ventricular assist device; LVEDD = left ventricular end-diastolic diameter; LVEF = left ventricular ejection fraction; VA = ventricular arrhythmia; VT = ventricular tachycardia.

basal region $[\mathrm{n}=1])$. Of these 6 patients, 2 had ES recurrences during follow-up, 1 died 65 days after the occurrence of ES, 4 were heart transplanted, and 1 was alive at the end of follow-up. Of note, no LV- or LVAD-related thrombosis was reported after VT ablation.

\section{Clinical outcomes after ES}

The occurrence of ES was associated with a high early mortality. As shown in the Kaplan-Meier curve in Figure 3A, 11 patients $(18.0 \%)$ died within 24 hours of ES, 20 patients (33.0\%) died within the first 2 weeks of ES, and 28 patients $(41.0 \%)$ died during the first 2 months. Notably, as illustrated in Figure 3B, patients experiencing ES had a significantly lower 1-year survival rate than did those free from ES $(P=.039)$.

Of the 20 deaths during the first 2 weeks, 15 were due to ES (as a consequence of multiple organ failure and/or right ventricular dysfunction), 1 due to LVAD thrombosis, 2 due to sep- tic shock, 1 due to hemorrhagic shock, and 1 due to a stroke. Twenty-two patients $(36.0 \%)$ presented at least 1 recurrence of ES, occurring a median of 43.0 (IQR 8.0-69.0) days after the initial ES. Eight of these patients died, including 7 because of the second ES (death occurring 8 [0.75-22.0] days after ES recurrence), and 1 patient had a fatal stroke 1 year later. The remaining 14 patients were still alive after 225.0 (IQR 31.0 538.0) days of follow-up. The causes of deaths in the study population are presented in Table 3. Of note, the rate of arrhythmic death did not differ between patients implanted and those not implanted with an ICD. Of 61 patients with ES, $16(26.0 \%)$ were transplanted after a median of 188.5 (IQR 52.0-565.0) days of the occurrence of ES.

\section{Discussion \\ Main results}

The main results of this study are as follows: (1) Almost $10 \%$ of patients implanted with an LVAD will present 
Table 2 Multivariate analysis for risk prediction of ES

\begin{tabular}{|c|c|c|c|}
\hline Variable & $\beta$ coefficient & $\begin{array}{l}\text { Multivariate } \\
\text { hazard ratio } \\
\text { ( } 95 \% \text { confidence } \\
\text { interval) }\end{array}$ & $P$ \\
\hline $\begin{array}{l}\text { VAs before LVAD } \\
\text { implantation }\end{array}$ & 0.963 & $2.620(1.484-4.627)$ & .0 \\
\hline $\begin{array}{l}\text { Heart failure duration } \\
>84 \mathrm{mo}\end{array}$ & 0.676 & $1.966(1.074-3.597)$ & .0 \\
\hline BMI $>24.5 \mathrm{~kg} / \mathrm{m}^{2}$ & 0.556 & $981-3.097)$ & .0 \\
\hline $\begin{array}{l}\text { Bilirubin level } \\
>22 \mathrm{mmol} / \mathrm{L}\end{array}$ & 0.518 & $1.679(0.993-2.839)$ & \\
\hline LVEDD > $71 \mathrm{~mm}$ & 0.276 & $1.318(0.737-2.357)$ & .35 \\
\hline $\begin{array}{l}\text { ICD before LVAD } \\
\text { implantation }\end{array}$ & 0.221 & $1.247(0.595-2.614)$ & \\
\hline
\end{tabular}

Values are presented as median (interquartile range) or as $\mathrm{n}(\%)$.

Receiver operating characteristic curves were used to dichotomize continuous variables with a $P$ value of $<.1$ in univariate analysis using the Youden's index to choose the optimal cutoff, as described above.

$\mathrm{BMI}=$ body mass index; $\mathrm{ES}=$ electrical storm; ICD = implantable cardioverter-defibrillator; $L$ VAD = left ventricular assist device; $L V E D D=$ left ventricular end-diastolic diameter; VA = ventricular arrhythmia.

ES after mid-term follow-up; (2) history of VAs before LVAD implantation and long heart failure duration are predictors of the occurrence of ES during follow-up; and (3) ES in patients with an LVAD is a severe event, and onethird of the patients presenting ES will die within 15 days of the arrhythmic event.

\section{VAs in patients with an LVAD}

VAs in patients with an LVAD can occur early during the postoperative period or later during long-term follow-up. Data on early VAs are scarce, but have been shown to occur in 1 in every 4 patients. ${ }^{2,3}$ Mechanisms such as suction, ionotropic medication, ionic imbalance, or high catecholamine state can precipitate early VAs, although many early VAs occur despite any identifiable factor. ${ }^{2}$ Early VAs significantly increase postoperative mortality, ${ }^{3}$ although no impact on long-term survival was observed. A history of VAs, ${ }^{2,3}$ age, ${ }^{2}$ non-ischemic cardiomyopathy, ${ }^{2}$ and a history of cardiac surgery before LVAD implantation ${ }^{3}$ were described as predictors of early VAs. Late VAs have been thoroughly studied and are

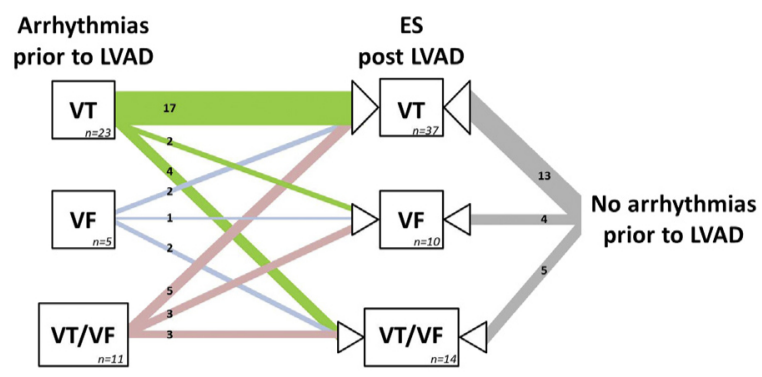

Figure 1 Relationship between the type of arrhythmias before LVAD implantation and the type of arrhythmias at the time of ES in 39 patients with a history of VAs and 22 patients with no history of VAs. ES = electrical storm; $\mathrm{LVAD}=$ left ventricular assist device; $\mathrm{VA}=$ ventricular arrhythmia; $\mathrm{VF}=$ ventricular fibrillation; VT $=$ ventricular tachycardia.

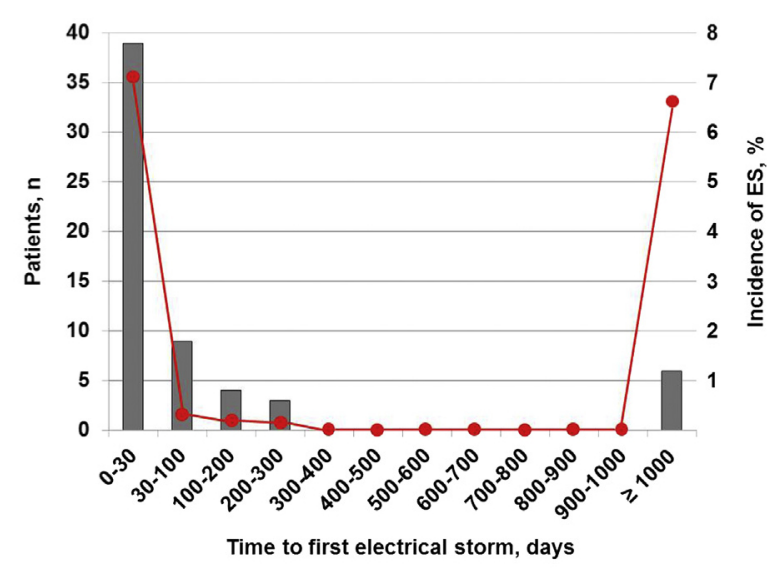

Figure 2 Temporal trend in the occurrence of ES. The absolute number of patients with a first episode of ES and the respective incidence are depicted as gray bars and red dots, respectively. ES = electrical storm.

often the consequence of the underlying cardiomyopathy. A wide range of incidence was described (from 11.6\% to $39.0 \%),{ }^{3-9}$ and the clinical impact of late VAs is still controversial since most of the patients are implanted with an ICD quickly detecting and terminating VT before an overt hemodynamic consequence may occur. Many predictors of late VAs were described in the literature, ${ }^{4-6,8,9}$ recently summarized in the larger series published so far as the VT-LVAD score ${ }^{6}$ (predictors: history of VAs, no angiotensin-converting enzyme inhibitors, heart failure duration $>12$ months, early VAs after implantation, and history of atrial fibrillation and non-ischemic cardiomyopathy).

To our knowledge, only 1 study specifically evaluated the incidence and clinical consequences of ES in LVAD recipients. ${ }^{11}$ Forty-three patients implanted with HeartMate II were included and followed for $18.5 \pm 18.5$ months. Of these patients, $12(27.9 \%)$ experienced ES after an average of $9.1 \pm$ 7.8 days and most of them during the initial 2 weeks after implantation. Early ES was associated with a significantly higher mortality rate at 1 month, although 1-year survival did not differ between patients having experienced and those not having experienced ES. In our larger population of 652 patients, a lower ES incidence of $9.4 \%$ was observed, a comparable rate as described in patients with an ICD implanted in primary (4\% after 20.6 months $)^{12}$ or secondary $(10 \%-20 \%)$ prevention. $^{13}$

As shown in Figure 2, the large majority of episodes occurred during the first month after implantation. As stated above, the postoperative period is a critical time point for the occurrence of VAs. Ionotropic drugs or electrolyte imbalance may predispose to VAs and specifically to ES. ${ }^{2}$ A transient postoperative QT interval prolongation has also been described and may contribute to the occurrence of VAs and ES. ${ }^{14}$ Interestingly, the incidence of ES tended to decrease over the first year, suggesting an anti-arrhythmic-like mechanism of LVAD. Indeed, few studies showed that the rate of VAs was reduced in patients with an LVAD, ${ }^{15}$ probably explained by an initial reverse ventricular remodeling at the molecular level, ${ }^{16}$ maybe because of ventricular unloading. However, the arrhythmic substrate may progress later, 
A

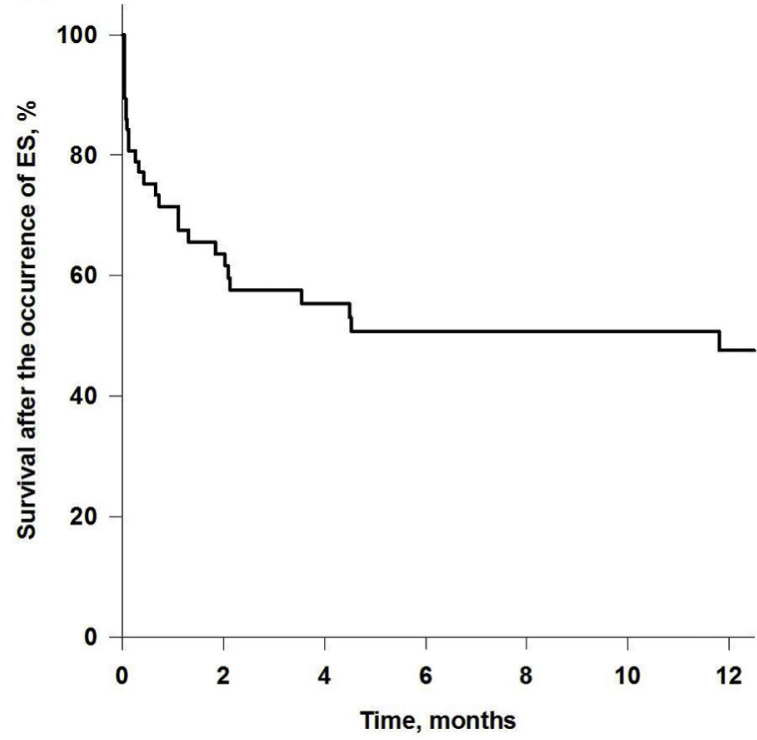

B

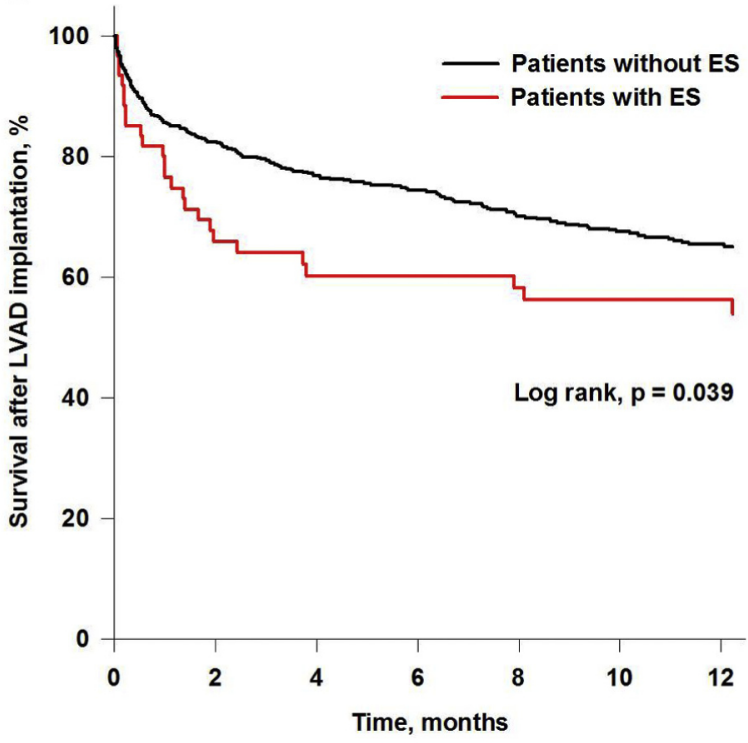

Figure 3 Kaplan-Meier survival curve. A: Survival probability after the occurrence of ES. B: Survival probability after LVAD implantation, depending on the occurrence of ES during follow-up. ES = electrical storm; LVAD = left ventricular assist device.

explaining the recrudescence of ES after few years of followup, as observed in our study. Lastly, as previously demonstrated in populations with an ICD, ${ }^{17}$ we show that a history of VAs increased the risk of ES in patients with an LVAD.

\section{Impact of ES on clinical outcomes}

The adverse prognosis of ES has been thoroughly studied. A meta-analysis comprising 857 patients with ES demonstrated a 3-fold increased risk of death. ${ }^{17}$ A negative impact on hospitalization rates and patients' quality of life was described. ${ }^{17}$ In our study, a similar negative impact of ES was observed. Indeed, a high mortality rate was observed on the following days and weeks after ES, with the vast majority of deaths being directly due to ES.

Table 3 Causes of deaths

\begin{tabular}{|c|c|c|c|}
\hline Variable & $\begin{array}{l}\text { Patients } \\
\text { with ES } \\
(n=61)\end{array}$ & $\begin{array}{l}\text { Patients } \\
\text { without ES } \\
(\mathrm{n}=591)\end{array}$ & $P$ \\
\hline Total death & $33(54.0)$ & $258(44.0)$ & .154 \\
\hline \multicolumn{4}{|l|}{ Cause of death } \\
\hline Cardiovascular death & $24(73.0)$ & $101(39.0)$ & \\
\hline Noncardiovascular death & $9(27.0)$ & $153(59.0)$ & .001 \\
\hline Unknown cause & $0(0)$ & $4(2.0)$ & \\
\hline \multicolumn{4}{|l|}{ Cardiovascular death } \\
\hline LVAD thrombosis & $2(8.0)$ & $28(28.0)$ & \\
\hline Right ventricular failure & $4(17.0)$ & $50(49.0)$ & \\
\hline Electrical storm & $17(71.0)$ & $0(0.0)$ & $<.001$ \\
\hline LVAD dysfunction & $1(4.0)$ & $1(1.0)$ & \\
\hline Others & $0(0.0)$ & $9(9.0)$ & \\
\hline No precision & $0(0.0)$ & $13(13.0)$ & \\
\hline
\end{tabular}

Values are presented as $\mathrm{n}(\%)$.

ES = electrical storm; LVAD = left ventricular assist device
As recently demonstrated by Vergara et $a l,{ }^{18}$ patients with ES are the population with VT at the highest risk of recurrence and mortality. The mechanism leading to the higher mortality observed after ES is still a matter of debate, but may be the consequence of the arrhythmia itself; of the deleterious effect of the multiple cardioversion/defibrillation shocks delivered to restore sinus rhythm, inducing myocardial damage; or of the advanced cardiomyopathy presented by the patient. ${ }^{19}$ In our recent report on VA occurring lately after LVAD implantation, we showed that late VA did not increase mortality. Indeed, having just 1 isolated late VA or multiple ones separated by a certain period of time in a hemodynamically stable patient is probably less pejorative than having multiple repetitive episodes of arrhythmias within 24 hours, specifically during the postoperative period, where patients are more prone to hemodynamic instability and electrical disturbances, potentially explaining the adverse outcomes observed.

However, successful radiofrequency ablation of VAs has been shown to improve survival in patients with ES, specifically in those with no inducible VT at the end of the procedure. ${ }^{18}$ Data on VA ablation in patients with an LVAD are scarce, but recent data reported the safety and efficacy of the procedure, with good arrhythmia-free survival after mid-term follow-up. ${ }^{20}$ To note, most of the VAs were related to the underlying substrate rather than the apical cannula. In our study, we found similar results with only 1 VT related to the LVAD cannula. Indeed, the underlying cardiomyopathy substrate was involved in the majority of targeted VTs.

Since VAs and specifically ES increase short-term mortality and since many electrophysiologists would be reluctant to perform ablation in a patient with an LVAD implanted, it would be interesting to analyze whether an invasive 
management of VAs before LVAD implantation would reduce the rate of VAs and thus improve survival. Further studies are warranted to validate this assumption. This is indeed crucial since epicardial VT ablation may be needed in some patients with non-ischemic cardiomyopathiesablation that cannot be performed after LVAD implantation. An intraoperative approach for VA ablation may also be discussed in such patients.

\section{Limitations}

This study has some limitations, including its retrospective design that may have affected the results. Specific antiarrhythmic drugs used during ES events were not available, and consequently, conclusions on outcomes depending on the treatment used cannot be drawn. Indeed, as stated above, successful radiofrequency ablation of VAs has been shown to improve outcomes and survival. $^{18}$ However, in our study, only 6 of 61 patients were offered an ablation procedure and therefore similar conclusions on outcomes or survival in patients with an LVAD cannot be drawn.

\section{Conclusion}

In this large multicenter study, we demonstrate a relatively high incidence of ES in patients with an LVAD. Indeed, 1 in every 10 patients will experience ES during follow-up, specifically those with a history of VAs before LVAD implantation, and occurring in the first postoperative month for two-thirds of them. The short-term mortality after ES is elevated, and one-third of the patients will die within 15 days. Whether invasive radiofrequency ablation of arrhythmias, in association with antiarrhythmic therapy, improves outcomes would require further studies.

\section{References}

1. Kirklin JK, Naftel DC, Kormos RL, et al. Interagency Registry for Mechanically Assisted Circulatory Support (INTERMACS) analysis of pump thrombosis in the
HeartMate II left ventricular assist device. J Heart Lung Transplant 2014; 33:12-22.

2. Garan AR, Levin AP, Topkara V, et al. Early post-operative ventricular arrhythmias in patients with continuous-flow left ventricular assist devices. J Heart Lung Transplant 2015:34:1611-1616.

3. Greet BD, Pujara D, Burkland D, et al. Incidence, predictors, and significance of ventricular arrhythmias in patients with continuous-flow left ventricular assist devices: a 15-year institutional experience. JACC Clin Electrophysiol 2017; $4: 257-264$

4. Efimova E, Fischer J, Bertagnolli L, et al. Predictors of ventricular arrhythmia after left ventricular assist device implantation: a large single-center observational study. Heart Rhythm 2017;14:1812-1819.

5. Enriquez AD, Calenda B, Miller MA, Anyanwu AC, Pinney SP. The role of implantable cardioverter-defibrillators in patients with continuous flow left ventricular assist devices. Circ Arrhythm Electrophysiol 2013;6:668-674.

6. Galand V, Flécher E, Auffret V, et al. Predictors and clinical impact of late ventricular arrhythmias in patients with continuous-flow left ventricular assist devices. JACC Clin Electrophysiol 2018;4:1166-1175.

7. Garan AR, Yuzefpolskaya M, Colombo PC, et al. Ventricular arrhythmias and implantable cardioverter-defibrillator therapy in patients with continuous-flow left ventricular assist devices: need for primary prevention? J Am Coll Cardiol 2013;61:2542-2550.

8. Oswald H, Schultz-Wildelau C, Gardiwal A, et al. Implantable defibrillator therapy for ventricular tachyarrhythmia in left ventricular assist device patients. Eur J Heart Fail 2010;12:593-599.

9. Yoruk A, Sherazi S, Massey HT, et al. Predictors and clinical relevance of ventricular tachyarrhythmias in ambulatory patients with a continuous flow left ventricular assist device. Heart Rhythm 2016;13:1052-1056.

10. Sagone A. Electrical storm: incidence, prognosis and therapy. J Atr Fibrillation 2015;8:1150.

11. Corre J, Picard F, Garcia R, et al. Electrical storm in the early phase of Heart-

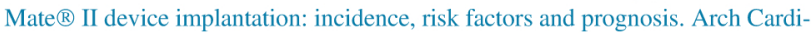
ovasc Dis 2018;111:332-339.

12. Sesselberg HW, Moss AJ, McNitt S, et al. Ventricular arrhythmia storms in postinfarction patients with implantable defibrillators for primary prevention indications: a MADIT-II substudy. Heart Rhythm 2007;4:1395-1402.

13. Exner DV, Pinski SL, Wyse DG, et al. Electrical storm presages nonsudden death: the Antiarrhythmics Versus Implantable Defibrillators (AVID) trial. Circulation 2001;103:2066-2071.

14. Harding JD, Piacentino V III, Gaughan JP, Houser SR, Margulies KB. Electrophysiological alterations after mechanical circulatory support in patients with advanced cardiac failure. Circulation 2001;104:1241-1247.

15. Rose EA, Gelijns AC, Moskowitz AJ, et al. Long-term use of a left ventricular assist device for end-stage heart failure. N Engl J Med 2001;345:1435-1443.

16. Heerdt PM, Holmes JW, Cai B, et al. Chronic unloading by left ventricular assist device reverses contractile dysfunction and alters gene expression in end-stage heart failure. Circulation 2000;102:2713-2719.

17. Guerra F, Shkoza M, Scappini L, Flori M, Capucci A. Role of electrical storm as a mortality and morbidity risk factor and its clinical predictors: a meta-analysis. Europace 2014;16:347-353.

18. Vergara P, Tung R, Vaseghi M, et al. Successful ventricular tachycardia ablation in patients with electrical storm reduces recurrences and improves survival. Heart Rhythm 2018;15:48-55.

19. Guerra F, Flori M, Bonelli P, Patani F, Capucci A. Electrical storm and heart failure worsening in implantable cardiac defibrillator patients. Europace 2014; $17: 247-254$.

20. Sacher F, Reichlin T, Zado ES, et al. Characteristics of ventricular tachycardia ablation in patients with continuous flow left ventricular assist devices. Circ Arrhythm Electrophysiol 2015;8:592-597. 